\title{
Molar Palatal Attachment - A Novel Appliance for Crossbite Correction
}

J alis Fatimaํㅗ Subrata Saha², Subir Sarkar ${ }^{3}$

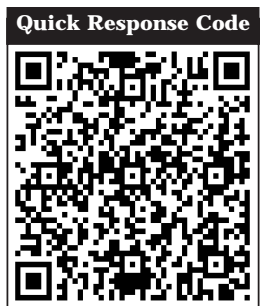

doi : 10.5866/2016.8.10115

${ }^{1}$ Post graduate student

${ }^{2}$ Professor

${ }^{3}$ Professor \& HOD

Department of Pedodontics

and Preventive Dentistry

Dr. R. Ahmed Dental College and Hospital

Kolkata

\section{Article Info:}

Received: April 10, 2016

Review Completed: May 11, 2016

Accepted: J une 10, 2016

Available Online: September, 2016 (www.nacd.in)

(C) NAD, 2016 - All rights reserved

\section{Email for correspondence:}

jlsfatima3@gmail.com

drssahakolkata@gmail.com

\begin{abstract}
:
Crossbite is an abnormal relation of one or more teeth of one arch to the opposing tooth or teeth of the other arch, in buccolingual direction in centric ocdusion caused by deviation of tooth/teeth position or abnormal jaw position. Crossbite can be dental or skeletal or functional in origin. It can be seen either in anterior teeth or posterior teeth. Posterior crossbite is less commonly seen clinically as compared to anterior crossbite and is also more compl ex to betreated. Various treatment modalities are available for its correction like interarch elastics, expansion screws either rapid or slow, hyrax appliance, quad helix, W arch appliance, molar palatal attachments etc.
\end{abstract}

Key words: Malocclusion, orthodontics, crossbite, appliance.

\section{INTRODUCTION}

Crossbite is an oftenly seen mal occlusion in day to day clinical practice. It is evident in numerous forms that is, anterior or posterior crossbites, whole arch or segmental crossbites, owing to number of contributing factors which may be dental or skel etal or functional in origin or a combination of these.

Dental causative factors like deviation of the eruption pathway of the tooth, prolonged retention of deciduo teeth dueto ankylosis or any other reason, premature exfoliation of the deciduous teeth, delayed eruption of permanent teeth due to thick fibrous gingiva interfering with eruption of teeth, involvement of patient in any kind of habit etc. ${ }^{1,2}$

Skel etal causative factors contributing to either anterior or posterior crossbite are those factors where in the skeletal jaw bases are at fault with no abnormality in dental components. These can belike narrow palate or narrow mandibular width which is relatively less common, short maxillary or mandibular jaw bases length in anteroposterior (saggital) plane, retarded forward growth of any one 
of the skeletal jaw base in relation to the other but with normal jaw base length, or excessive growth of one jaw in relation to the other jaw etc.

Functional crossbite occurs because of functional shift in mandible from centric relation to maximum intercuspation due to any premature contact of the malplaced tooth/teeth. In certain situations, a restorative treatment in a tooth may cause functional crossbite due to any interference from improperly restored tooth/teeth. Also, children with enlarged adenoids tend to bring their mandible in forward direction while occluding causing functional crossbite. Functional crossbites are oftenly called psuedocrossbites because of alike representation of crossbite while there is no dental or skeletal cause.

The present case mentioned here is of an isolated maxillary premolar in crossbite relation to its opposite teeth treated with the help of a novel customized appliance named as molar palatal attachment.

\section{CASE REPORT}

A 12 year old male patient had reported to the department of pedodontics and preventive dentistry with an isolated crossbite of maxillary left premolar and lateral incisor (Figure 1). The patient had been thoroughly examined for all the possible contributing factors and was found with no skeletal abnormality, or history of habit except the mal positioned maxillary left premolar which was in buccal crossbite in relation to the opposing teeth and palatally erupted maxillary left lateral incisor.

With all the different treatment option available, very few are available to treat or correct the position of single tooth. In this patient, crossbite of premolar was corrected first, by using a novel technique which was customized according to the need of the condition.

A curved bondable button was bonded on to the buccal surface of the premolar and elastic chain was engaged with this button to the customized hook which was fabricated from soldering two 19 gauge wire together to add to the strength and stability of the palatal attachment in a hook form and was then soldered to the molar band on the palatal side. To prevent any soft tissue injury, the pointed and rough end of the hook was rounded off by adding silver solder to its tip. Palatal attachment in the form of helix would not have been as stable and strong as hook, and could not have been made satisfactorily by soldering two 19 gauge wires if at all was attempted to increase its strength. The entire appliance set up was fixed in the patient's mouth by cementing the molar band onto the left maxillary first permanent molar and bite was raised by cementing an acrylic bite block on lower right posterior teeth to assist in unhindered tooth movement (Figure 2).

The elastic chain was changed weekly, reducing the number of intervening hol es by one hole per week until the desired position was obtained by taking advantage of stationary anchorage from maxillary first permanent molar with its higher anchorage value to tip the maxillary first premolar into its correct position and crossbite was corrected (Figure 3 and 4).

The entire treatment was completed in three weeks interval with no retention required as the corrected position of the involved tooth was self retained by the occlusal relationship with the teeth in opposite arch.

\section{DISCUSSION}

Crossbite because of any cause should be taken care of as early as its possibleto prevent the harmful and unwanted consequences of the same. Posterior crossbites especially those that result from functional shift of the mandible should be treated as soon as clinically feasible once they are detected because it may result in a number of sequel ae which can effect both hard and soft tissues. ${ }^{3-7}$ The sequel ae that may occur includes:

1) compensatory changes in the articulation of temporomandibular joint.

2) skeletal asymmetries 


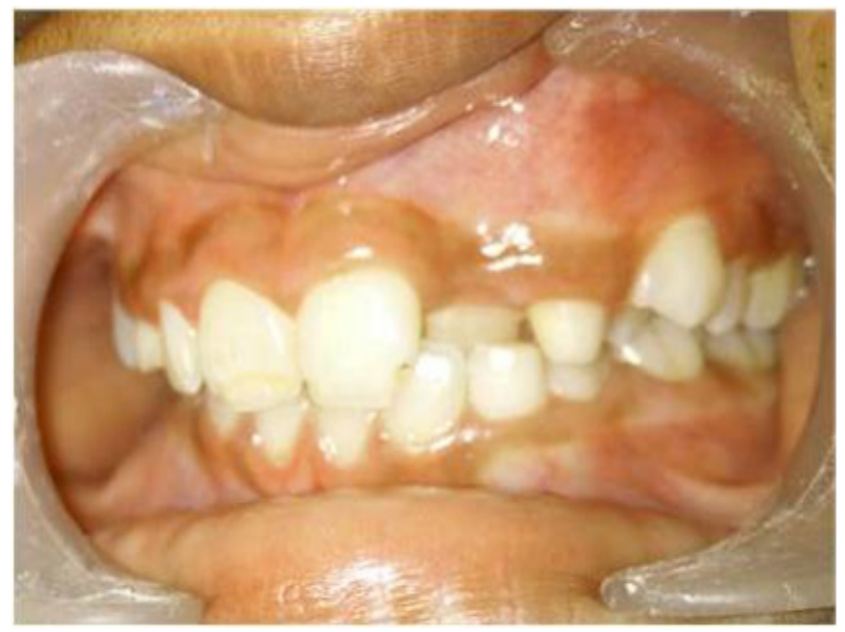

Figure 1: Intraoral preoperative picture showing crossbite of maxillary left premolar and lateral incisor

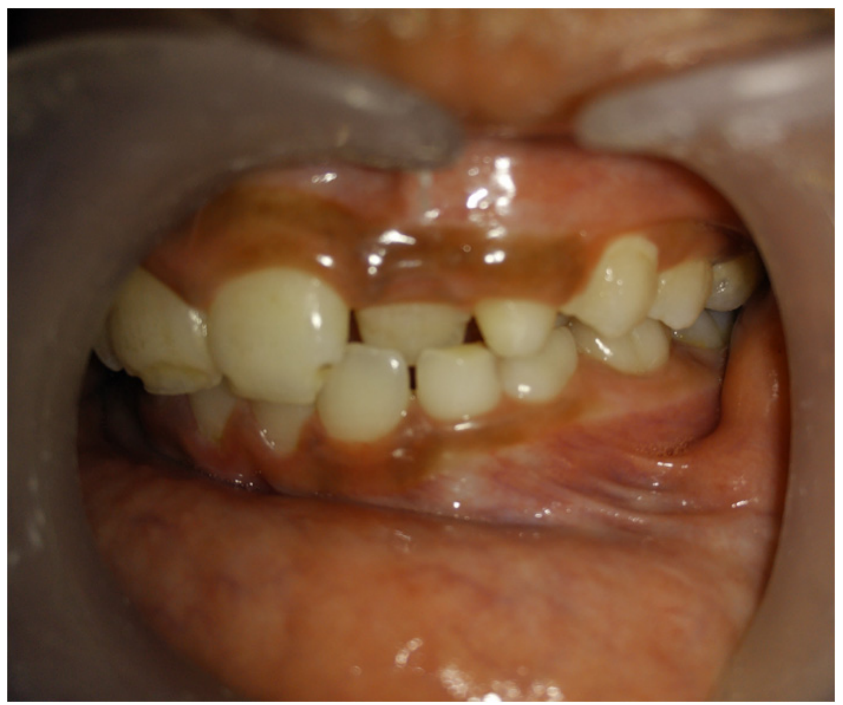

Figure 3: Post operative intraoral frontal view of the corrected maxillary first premolar

3) damage to the soft tissuelike gingival recession and loss of periodontal attachment due to nonaxial loading of the occlusal forces onto the tooth

4) attrition of the involved teeth

The type of device that is most frequently used is the acrylic-based removable appliance with 1 or more expansion screws in either arch..$^{8-10}$ Various treatment options are available to treat crossbite ,

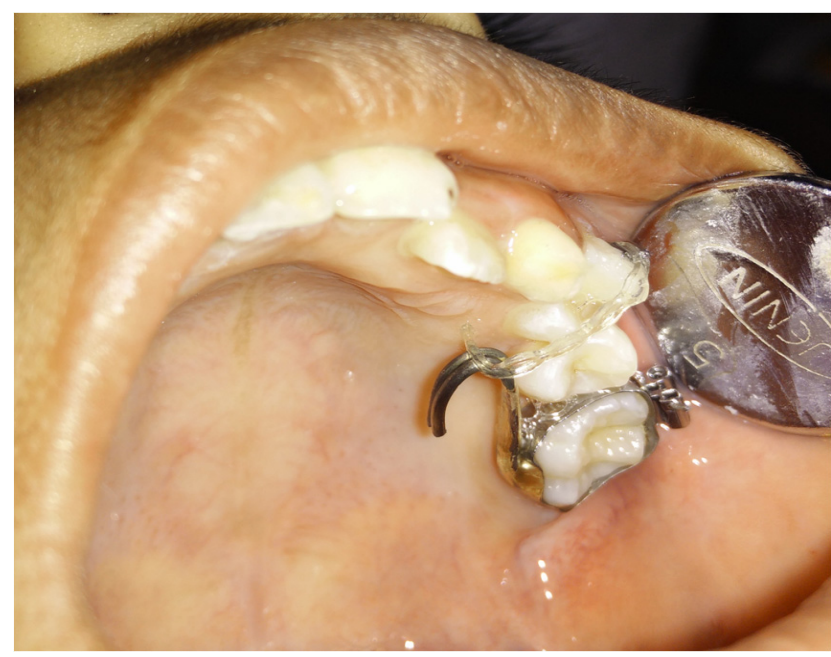

Figure 2: Intraoral occlusal view with appliance

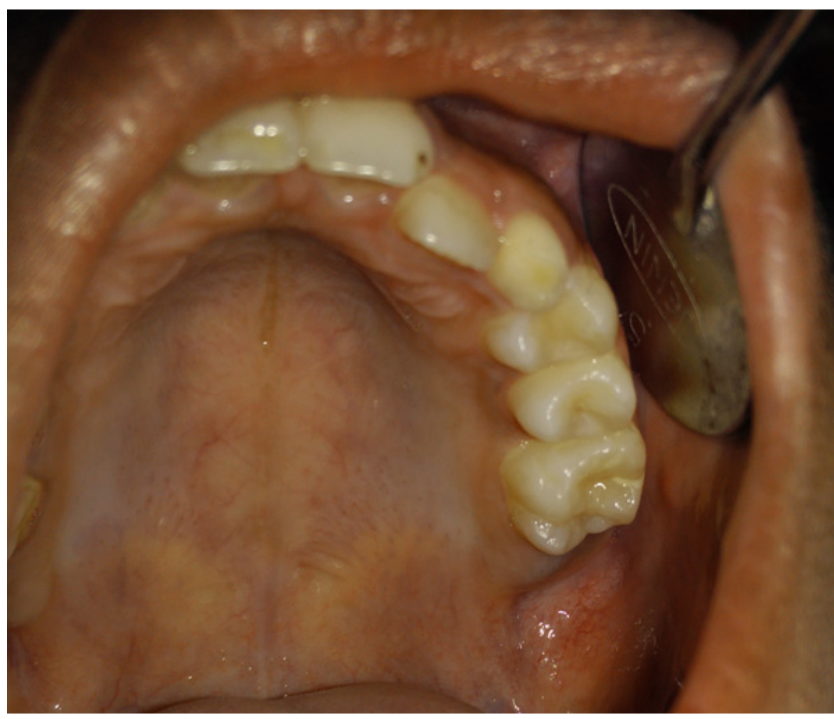

Figure 4: Post operative intraoral occlusal view of maxillary first premolar

but this case was opted to be treated with a molar palatal attachment as it provides several advantages over the other techniques like minimal number of teeth that is involved which thereby reduces the number of teeth over which orthodontic forces are acted upon and consequentially also reducing the inevitable pulpal or periodontal effects which occur after any orthodontic treatment. It also takes less chair side time in fixing the appliance in the mouth of patient. Being a fixed appliance, it obviates the 
necessity of patient cooperation in wearing of appliance. One added advantage of this appliance is its intra-arch fabrication that is not involving the opposite arch making it more patient friendly.

But with all the advantages, it has certain disadvantages too as with any other fixed appliance therapy like difficulty in oral hygiene maintainance and frequent weekly patient visit. But the short treatment time needed by this appliance makes its few disadvantages unnoticeable.

\section{CONCLUSION}

Fixed or removable maxillary and mandibular appliances that are used either to correct transverse relationships or to increase arch circumference or to correct the individual tooth position should be an integral part of a practitioner's armentarium. However, an appropriate diagnosis, list of the present problems and problems which may later become evident if not treated, and integrated long term treatment plan should first be developed.

\section{REFERENCES:}

1. Proffit WR, Fields HW, Moray LJ . Prevalence of orthodontic treatment need in the United States: Estimates for the NHANES-III survey. Int J Orthod Orthogn Surg. 1998; 13:97-106.

2. Brook PH, Shaw WC. The development of an index for orthodontictreatment priority. EurJ Orthod 1989; 11:309-332.
3. Proffit WR. Contemporary Orthodontics. 3rd ed. St.Louis: Mosby, Inc; 2000.

4. Nerder PH, Bakke M, Solow B, Begole E: The functional shift of the mandible in unilateral posterior crossbite and adaptation of the temporomandibular joints: A pilot study. Eur J Orthod. 1999; 21:155-156.

5. O'Byrn B, Sadowsky C, Schneider B, BeGole E. An evaluation of mandibular asymmetry in adults with unilateral posterior crossbite. Am J Orthod Dent Orthop 1995;107:394-400.

6. Cross D, McDonald J P. Effect of rapid maxillary expansion on skeletal, dental and nasal structure: A postero-anterior cephalometric study. Eur J Orthod 2000; 22:519-528.

7. Hess K,Artun J, J oondeph D, Kennedy DB. Changes in condylar position and occlusion associated with maxillary expansion for correction of functional unilateral crossbite. Am J Orthod Dent Orthop 1997; 111:410-418.

8. Sandikcioglu M, Hazar S. Skel etal and dental changes after maxillary expansion in the mixed dentition. Am J Orthod Dent Orthop 1997; 111:321-327.

9. Hermanson $\mathrm{H}, \mathrm{Kurol} \mathrm{J}$, Ronnerman A. Treatment of unilateral posterior crossbite with quad- helix and removable plates. A retrospective study. Eur J Orthod 1985; 7:97-102.

10. Hicks E. Slow maxillary expansion: A clinical study of the skeletal versus dental response to low magnitude force. Am J Orthod 1978; 73:121-141.

\section{Gain quick access to our journal online View our journal at www.nacd.in}

